\title{
Synthesis and evaluation of Camptothecin antibody-drug conjugates
}

Supplementary Section

Contents

Abbreviations:

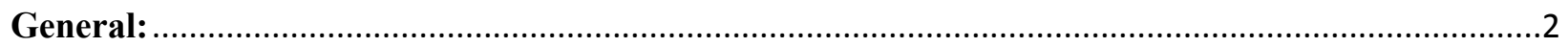

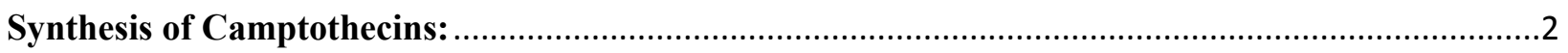

General method for the preparation of ADCs (Example mAb $\left.\mathbf{A b}_{\mathrm{E}}-21 \mathrm{a}\right)$ : .......................................16

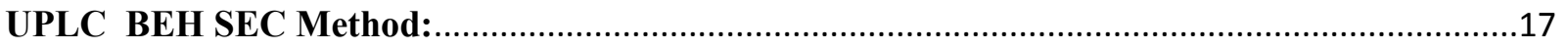

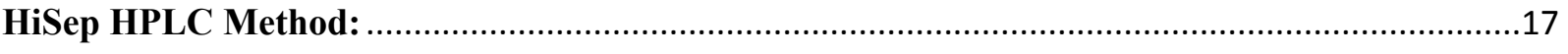

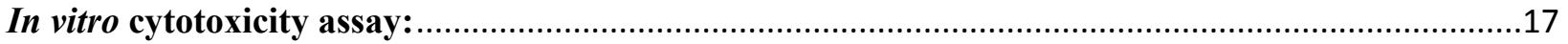

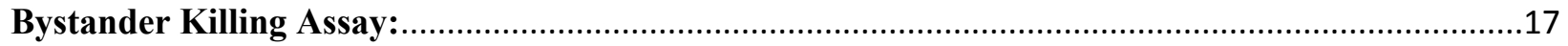

In vivo efficacy of ADCs in mouse xenograft models:.................................................................18

Pharmacokinetic studies on $\mathrm{mAb}_{\mathrm{E}}-21 \mathrm{a}$ and $\mathrm{mAb}_{\mathrm{E}}-21 d \mathrm{ADCs}$ in mice: ........................................19

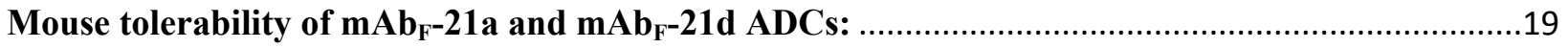

\begin{abstract}
Abbreviations:
ADC, antibody-drug conjugate; Bn, benzyl; DAR, drug per antibody ratio; DIPEA, $N, N$ -

Diisopropylethylamine; DMF, $N, N$-dimethylformamide; DCM, dichloromethane; DMSO, dimethylsulfoxide; DMTMM, (4-(4,6-dimethoxy-1,3,5-triazin-2-yl)-4-methyl-morpholinium chloride); $\mathrm{Et}_{3} \mathrm{~N}$, triethylamine; Fmoc, 9-Fluorenylmethoxycarbonyl; HMPA, Hexamethyl phosphoramide; NHS, $N$-hydroxysuccinimide ester; NMM, $N$-methyl morpholine; TCEP, tris(2carboxyethyl)phosphine; TFA, trifluoroacetic acid; SEC, size-exclusion chromatography; Z, benzyloxycarbonyl.
\end{abstract}




\section{General:}

The compound (S)-4-Ethyl-4-hydroxy-7,8-dihydro-1H-pyrano[3,4-f]indolizine-3,6,10(4H)trione (8) was purchased from AchemBlock. All other compounds were purchased from SigmaAldrich of Chem. Impex. All synthetic reactions were conducted under an argon atmosphere with magnetic stirring unless otherwise stated. Proton magnetic resonance ( $\left.{ }^{1} \mathrm{H} \mathrm{NMR}\right)$ and carbon magnetic resonance spectra $\left({ }^{13} \mathrm{C} N \mathrm{NM}\right)$ were obtained on a Bruker Avance 400 spectrometer operating at 400 and $101 \mathrm{MHz}$, respectively. The NMR chemical shifts are reported in $\delta$ values relative to the NMR solvent. Lyophilizations were performed using a VerTis Benchtop K. Flash chromatography was performed on an Teledyne Combiflash system. HPLC purifications were performed using Gilson 334 pumps in series with a Gilson UV/vis-156 dual wavelength detector and a Gilson FC204 fraction collector. High resolution mass spectra (HRMS) were obtained on a Thermo Fisher Q-Exactive instrument.

\section{Synthesis of Camptothecins:}
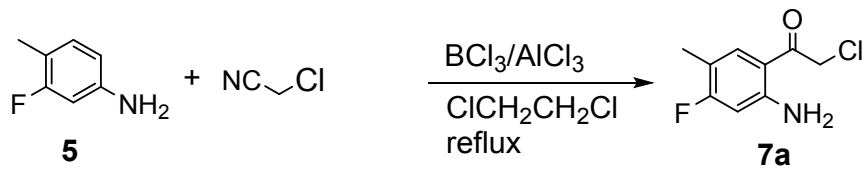

7a: To flask containing anhydrous 1,2-dichloroethane $(80 \mathrm{~mL})$ was added $1 \mathrm{M}$ boron trichloride in dichloromethane $(16 \mathrm{~mL}, 16 \mathrm{mmol})$ then cooled to $0{ }^{\circ} \mathrm{C}$ with an ice water bath. $5(2.5 \mathrm{~g}, 20$ mmol) was added in portions then stirred at $0{ }^{\circ} \mathrm{C}$ for $10 \mathrm{~min}$, then chloroacetonitrile $(2.7 \mathrm{~mL}$, $23.5 \mathrm{mmol})$ was added followed by the addition of aluminum chloride $(3.5 \mathrm{~g}, 26 \mathrm{mmol})$. The ice bath was removed and the reaction solution was gradually warmed to room temperature. After stirring at room temperature for $10 \mathrm{~min}$, the reaction mixture was heated at reflux for $39 \mathrm{~h}$. The reaction solution was cooled to room temperature and cold water $(40 \mathrm{~mL})$ was added slowly followed by the addition of $5 \% \mathrm{HCl}$ water solution. After $30 \mathrm{~min}$, it was diluted with dichloromethane $(80 \mathrm{~mL})$. The organic layer was washed with water and brine, dried over anhydrous sodium sulfate and filtered. The filtrate was stripped under reduced pressure and the residue was purified by reverse phase HPLC (200 g C18 column, $80 \mathrm{~mL} / \mathrm{min}, \mathrm{CH}_{3} \mathrm{CN} / \mathrm{H}_{2} \mathrm{O}, 25 \%$ $\mathrm{CH}_{3} \mathrm{CN}$ for $5 \mathrm{~min}$ then to $95 \% \mathrm{CH}_{3} \mathrm{CN}$ in $22 \mathrm{~min}$ then $95 \% \mathrm{CH}_{3} \mathrm{CN}$ for $5 \mathrm{~min}$ ) to give compound 7a as an off-white solid (1.52 g, yield 38\%). MS (ESI): $(\mathrm{M}+\mathrm{H})^{+}$calcd. 202.0, found 202.2. 


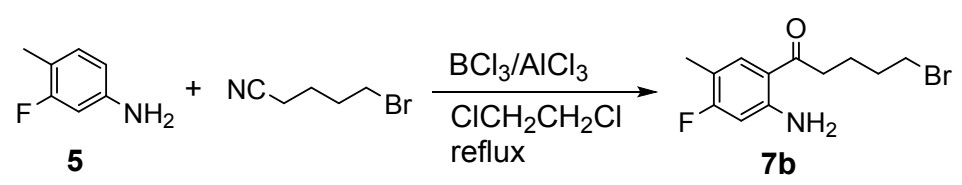

7b: To a flask containing anhydrous 1,2-dichloroethane $(50 \mathrm{~mL})$ was added $1 \mathrm{M}$ boron trichloride in dichloromethane $(9.95 \mathrm{~mL}, 9.95 \mathrm{mmol})$ then cooled to $0{ }^{\circ} \mathrm{C}$ with an ice water bath. $5(1.56 \mathrm{~g}, 12.4 \mathrm{mmol})$ was added in portions then stirred at $0{ }^{\circ} \mathrm{C}$ for $10 \mathrm{~min}$, then 5 bromovaleronitrile $(1.72 \mathrm{~mL}, 14.9 \mathrm{mmol})$ was added followed by the addition of aluminum chloride (2.16 g, $16.2 \mathrm{mmol})$. The ice bath was removed and the reaction solution was gradually warmed to room temperature. After stirring at room temperature for $10 \mathrm{~min}$, the reaction mixture was heated at reflux for $39 \mathrm{~h}$. The reaction solution was cooled to room temperature and cold water $(25 \mathrm{~mL})$ was added slowly followed by the addition of $5 \% \mathrm{HCl}$ water solution. After $30 \mathrm{~min}$, it was diluted with dichloromethane $(50 \mathrm{~mL})$. The organic layer was washed with water and brine, dried over anhydrous sodium sulfate and filtered. The filtrate was stripped under reduced pressure and the residue was purified by reverse phase HPLC (100 g C18 column, $\mathrm{CH}_{3} \mathrm{CN} / \mathrm{H}_{2} \mathrm{O}, 25 \% \mathrm{CH}_{3} \mathrm{CN}$ for 5 min then to $95 \% \mathrm{CH}_{3} \mathrm{CN}$ in $15 \mathrm{~min}$ then $95 \% \mathrm{CH}_{3} \mathrm{CN}$ for 5 min) to give compound $7 \mathbf{b}$ as an off-white solid (1.42 g, yield 40\%). MS (ESI): $(\mathrm{M}+\mathrm{H})^{+}$calcd. (288.0 and 290.0), found (288.2 and 290.1).<smiles>Cc1cc(C(=O)CCl)c(N)cc1F</smiles>

$7 a$

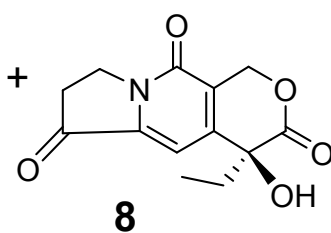

8

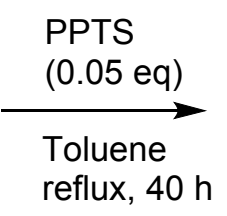

reflux, $40 \mathrm{~h}$

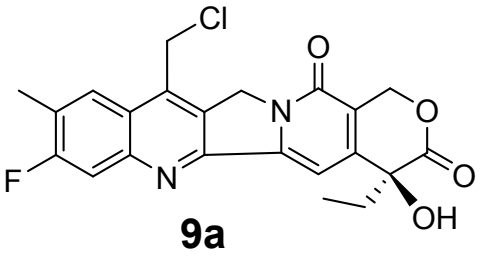

$9 a$

9a: Compound 7a $(3.15 \mathrm{~g}, 15.64 \mathrm{mmol}), 8(3.92 \mathrm{~g}, 14.89 \mathrm{mmol})$ in toluene $(200 \mathrm{~mL})$ and PPTS (37 mg, $0.15 \mathrm{mmol}$ ) were suspended in a $50 \mathrm{~mL}$ flask equipped with a reflux condenser containing anhydrous toluene $(10 \mathrm{~mL})$. The reaction was heated at reflux for $40 \mathrm{~h}$ with magnetic stirring under an argon atmosphere over night then allowed to cool to room temperature. The mixture was vacuum filtered and the solids were washed with toluene $(5 \mathrm{~mL})$ to give $9 \mathbf{a}(4.74 \mathrm{~g})$ in 74\% yield. ${ }^{1} \mathrm{H}$ NMR (400 MHz, DMSO-d6) $\delta 8.37(\mathrm{~d}, J=8.3,1.2 \mathrm{~Hz}, 1 \mathrm{H}), 8.10-7.90$ (m, 1H), $7.33(\mathrm{~d}, J=2.1 \mathrm{~Hz}, 1 \mathrm{H}), 6.55(\mathrm{~d}, J=4.8 \mathrm{~Hz}, 1 \mathrm{H}), 5.85-5.20(\mathrm{~m}, 6 \mathrm{H}), 2.61-2.45(\mathrm{~m}, 3 \mathrm{H})$, $1.98-1.76(\mathrm{~m}, 2 \mathrm{H}), 0.89(\mathrm{t}, J=7.3 \mathrm{~Hz}, 3 \mathrm{H})$. HRMS $(\mathrm{M}+\mathrm{H})^{+}$calcd. 429.1017, found 429.1023. 


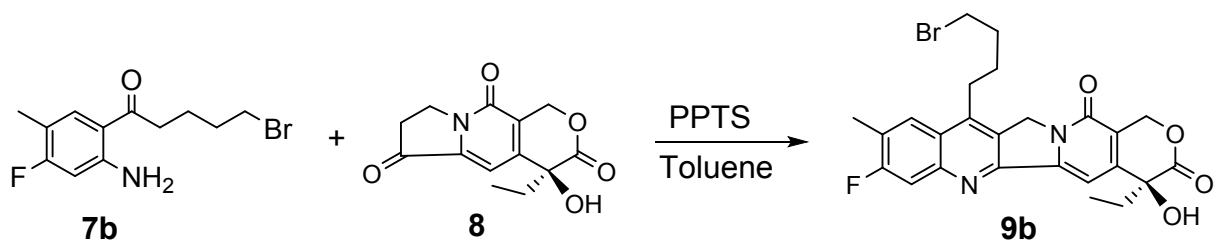

9b: Compound 7b (1.695 g, $5.88 \mathrm{mmol})$ and compound $\mathbf{8}(1.548 \mathrm{~g}, 5.88 \mathrm{mmol})$ in toluene (50 $\mathrm{mL}$ ) with PPTS (0.074 g, $0.294 \mathrm{mmol})$ were magnetically stirred at refluxed for 22 . Solvent was evaporated and residue was taken up in a minimum volume of $10 \%$ methanol in $\mathrm{CH}_{2} \mathrm{Cl}_{2}$ then purified by silica gel chromatography ( $40 \mathrm{~g}$ silica column, $\mathrm{CH}_{2} \mathrm{Cl}_{2} / \mathrm{MeOH}, 0$ to $10 \% \mathrm{MeOH}$ over $20 \mathrm{~min}$ ) to give $9 \mathbf{b}(2.56 \mathrm{~g})$ in $84 \%$ yield. ${ }^{1} \mathrm{H}$ NMR (400 MHz, DMSO-d6) $\delta 8.39-8.17$ (m, $1 \mathrm{H}), 7.89(\mathrm{~d}, J=10.9 \mathrm{~Hz}, 1 \mathrm{H}), 7.31(\mathrm{~s}, 1 \mathrm{H}), 6.52(\mathrm{~d}, J=6.2 \mathrm{~Hz}, 1 \mathrm{H}), 5.44(\mathrm{~s}, 2 \mathrm{H}), 5.31(\mathrm{~s}, 2 \mathrm{H})$, $3.65(\mathrm{t}, J=6.7 \mathrm{~Hz}, 2 \mathrm{H}), 3.28-3.09(\mathrm{~m}, 2 \mathrm{H}), 2.51(\mathrm{t}, J=1.8 \mathrm{~Hz}, 3 \mathrm{H}), 2.15-1.95(\mathrm{~m}, 2 \mathrm{H}), 1.95$ $-1.71(\mathrm{~m}, 4 \mathrm{H}), 0.88(\mathrm{t}, J=7.4 \mathrm{~Hz}, 3 \mathrm{H})$. HRMS $(\mathrm{M}+\mathrm{H})^{+}$calcd. 515.0981, found 515.0992.
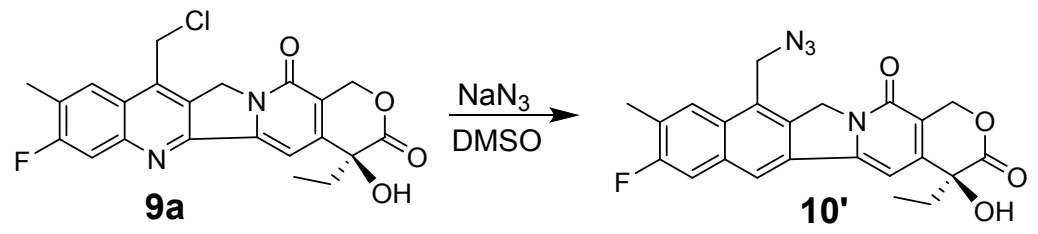

10': The solution of 9a ( $2 \mathrm{~g}, 4.66 \mathrm{mmol})$ and sodium azide $(0.455 \mathrm{~g}, 7.0 \mathrm{mmol})$ in $25 \mathrm{~mL}$ anhydrous DMSO was stirred at room temperature for $6 \mathrm{~h}$ followed by dilution with $200 \mathrm{~mL}$ deionized water. The product precipitated and was collected by filtration. It was dried by air to give 10' $(2.03 \mathrm{~g})$ in quantitative yield. MS (ESI): $(\mathrm{M}+\mathrm{H})^{+}$calcd. 435.1, found 436.2, MS (ESI): (M - H)- calcd. 433.1, found 434.2.
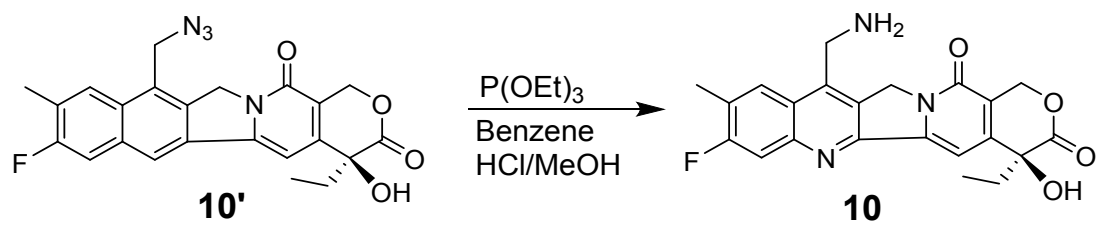

10: To a solution of 10' $(2.03 \mathrm{~g}, 4.66 \mathrm{mmol})$ in anhydrous benzene $(60 \mathrm{~mL})$ was added triethyl phosphite (1.94 g, $11.66 \mathrm{mmol}$ ) and the solution was flushed with argon then heated at reflux for $4 \mathrm{~h}$. The reaction solution was cooled to room temperature and $3 \mathrm{M}$ methanolic $\mathrm{HCl}(30 \mathrm{~mL})$ was added and heated at reflux $\left(80^{\circ} \mathrm{C}\right.$ bath) for $38 \mathrm{~h}$. The reaction solution was cooled to room temperature. It was filtered to give $\mathbf{1 0}(1.016 \mathrm{~g})$ as off-white solid. The filtrate was concentrated and the residue was purified by silica gel chromatography (12 g silica column, $\mathrm{CH}_{2} \mathrm{Cl}_{2} / \mathrm{MeOH}, 0$ 
to $20 \% \mathrm{MeOH}$ in $16 \mathrm{~min})$ to give more $\mathbf{1 0}(0.079 \mathrm{~g}) .1 .09 \mathrm{~g}$ of $\mathbf{1 0}$ was obtained (yield $57 \%) .{ }^{1} \mathrm{H}$ NMR (400 MHz, DMSO-d6) $\delta 8.62$ (s, 3H), 8.43 (d, $J=8.0 \mathrm{~Hz}, 1 \mathrm{H}), 7.99(\mathrm{~d}, J=10.7 \mathrm{~Hz}, 1 \mathrm{H})$, 7.35 (s, 1H), 5.59 (s, 2H), 5.45 (s, 2H), 4.70 (d, $J=6.0 \mathrm{~Hz}, 2 \mathrm{H}), 2.55$ (s, 3H), 1.88 (hept, $J=7.1$ $\mathrm{Hz}, 2 \mathrm{H}), 0.88(\mathrm{t}, J=7.3 \mathrm{~Hz}, 3 \mathrm{H})$. MS (ESI): $(\mathrm{M}+\mathrm{H})^{+}$, calcd. 410.2, found 410.4 .

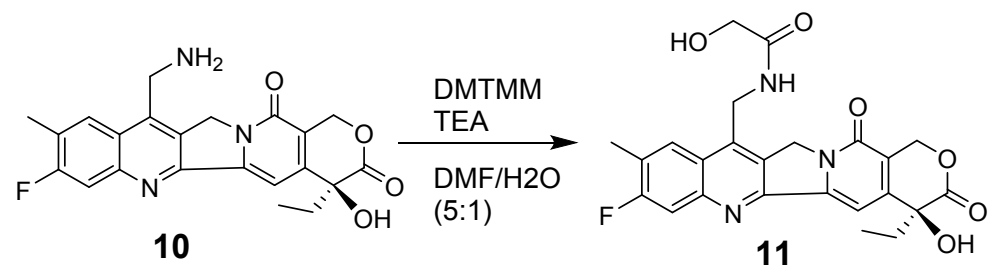

11: To the solution of $\mathbf{1 0}(7.5 \mathrm{mg}, 0.018 \mathrm{mmol})$ in DMF $(0.5 \mathrm{~mL})$ was added triethylamine $(2.6$ $\mu \mathrm{L}, 0.018 \mathrm{mml})$ and glycolic acid $(1.5 \mathrm{mg}, 0.020 \mathrm{mmol})$. The solution was cooled to $0{ }^{\circ} \mathrm{C}$ with an ice bath and DMTMM (10.1 mg, $0.037 \mathrm{mmol})$ in deionized water $(0.1 \mathrm{~mL})$ was added. The ice bath was removed and the reaction mixture was stirred at room temperature for $2 \mathrm{~h}$. The reaction solution was stripped under reduced pressure and the residue was purified by silica gel chromatography ( $4 \mathrm{~g}$ silica column, $\mathrm{CH}_{2} \mathrm{Cl}_{2} / \mathrm{MeOH}, 0$ to $20 \% \mathrm{MeOH}$ in $15 \mathrm{~min}$ ) to give the desired product 11 (8 mg, yield 93\%). ${ }^{1} \mathrm{H}$ NMR (400 MHz, DMSO-d6) $\delta 0.88(\mathrm{t}, J=7.3 \mathrm{~Hz}$, $3 \mathrm{H}), 1.79-1.98(\mathrm{~m}, 3 \mathrm{H}), 2.55(\mathrm{~s}, 0 \mathrm{H}), 3.84(\mathrm{~d}, J=5.6 \mathrm{~Hz}, 3 \mathrm{H}), 4.85(\mathrm{~d}, J=6.0 \mathrm{~Hz}, 2 \mathrm{H}), 5.44(\mathrm{~s}$, $3 \mathrm{H}), 5.51(\mathrm{~s}, 2 \mathrm{H}), 5.58(\mathrm{t}, J=5.7 \mathrm{~Hz}, 1 \mathrm{H}), 6.53(\mathrm{~s}, 1 \mathrm{H}), 7.32(\mathrm{~s}, 1 \mathrm{H}), 7.90(\mathrm{~d}, J=10.8 \mathrm{~Hz}, 1 \mathrm{H})$, $8.48(\mathrm{~d}, J=1.2,8.3 \mathrm{~Hz}, 1 \mathrm{H}), 8.76$ (t, $J=6.0 \mathrm{~Hz}, 1 \mathrm{H}) .{ }^{13} \mathrm{C}$ NMR (101 MHz, DMSO-d6) $\delta 172.95$, $172.89,157.23,152.85,150.44,149.07,145.85,140.12,129.27,127.97,124.28,119.63,97.23$, $72.83,65.74,61.91,54.06,50.54,49.58,44.06,37.34,30.72,15.74,8.22$. HRMS (M+ H $)^{+}$ calcd. 468.1571 , found 468.1593 .

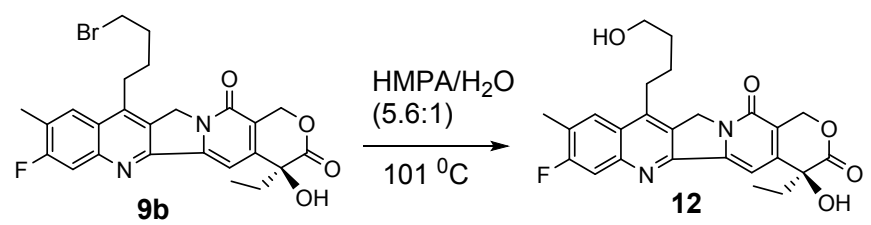

12: A solution of compound $9 \mathrm{~b}(860 \mathrm{mg}, 1.67 \mathrm{mmol})$ in HMPA $(5 \mathrm{~mL})$ and deionized water $(0.9$ $\mathrm{mL}$ ) was heated at $101^{\circ} \mathrm{C}$ for $18 \mathrm{~h}$. The reaction mixture was cooled to room temperature and the solution was loaded on a C18 cartridge and purified by reverse phase HPLC (30 g C18 column, $\mathrm{CH}_{3} \mathrm{CN} / \mathrm{H}_{2} \mathrm{O}, 25 \% \mathrm{CH}_{3} \mathrm{CN}$ for 3 min then to $95 \% \mathrm{CH}_{3} \mathrm{CN}$ in 15 min then $95 \% \mathrm{CH}_{3} \mathrm{CN}$ for $5 \mathrm{~min}$ ) to give $\mathbf{1 2}$ as a solid, contaminated with impurities. It was further purified by silica gel chromatography $\left(\mathrm{CH}_{2} \mathrm{Cl}_{2} / \mathrm{MeOH}, 0\right.$ to $20 \% \mathrm{MeOH}$ linear gradient over $\left.15 \mathrm{~min}\right)$ to give 392 mg of 12 as an off-white solid (51\% yield). ${ }^{1} \mathrm{H}$ NMR (400 MHz, Methanol- $\left.d_{4}\right) \delta 8.00(\mathrm{dd}, J=$ 8.2, 1.1 Hz, 1H), $7.52-7.33(\mathrm{~m}, 2 \mathrm{H}), 5.53(\mathrm{~d}, J=16.1 \mathrm{~Hz}, 1 \mathrm{H}), 5.33(\mathrm{~d}, J=16.1 \mathrm{~Hz}, 1 \mathrm{H}), 5.18$ 
- $4.96(\mathrm{~m}, 2 \mathrm{H}), 3.66(\mathrm{q}, J=7.2,6.7 \mathrm{~Hz}, 2 \mathrm{H}), 3.24-3.06(\mathrm{~m}, 2 \mathrm{H}), 2.45(\mathrm{dd}, J=20.1,2.7 \mathrm{~Hz}$, $3 \mathrm{H}), 1.94(\mathrm{tdd}, J=7.1,6.0,2.0 \mathrm{~Hz}, 2 \mathrm{H}), 1.88-1.66(\mathrm{~m}, 4 \mathrm{H}), 1.00(\mathrm{td}, J=7.4,2.5 \mathrm{~Hz}, 3 \mathrm{H}) .{ }^{13} \mathrm{C}$ NMR $\left(101 \mathrm{MHz}\right.$, Methanol- $\left.d_{4}\right) \delta 173.32,163.68,161.19,157.56,151.44,151.09,148.68$, 148.56, 146.06, 144.46, 128.10, 127.89, 127.22, 125.66, 125.60, 124.26, 118.92, 111.91, 111.69, 97.96, 72.74, 65.28, 60.97, 49.40, 32.15, 30.80, 29.00, 25.96, 14.09, 14.06, 6.75; HRMS (M + $\mathrm{H})^{+}$calcd. 453.1826, found 453.1832 .

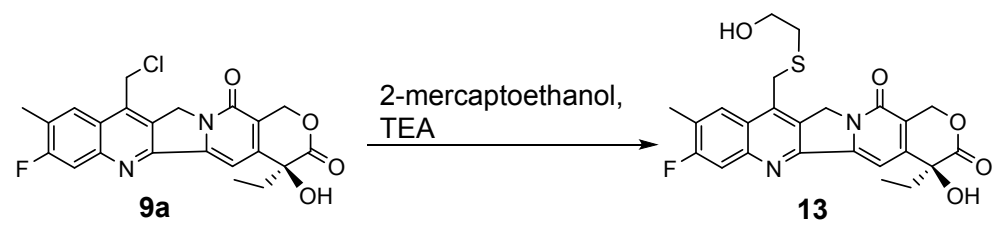

13: Compound 9a (100 mg, $0.23 \mathrm{mmol})$ was dissolved in anhydrous DMF (2 mL) to which was added 2-mercaptoethanol $(0.2 \mathrm{~mL}, 2.8 \mathrm{mmol})$ followed by TEA $(0.13 \mathrm{~mL}, 0.94 \mathrm{mmol})$ and magnetically stirred for $20 \mathrm{~min}$. The reaction mix was injected onto $250 \mathrm{~g}$ medium pressure $\mathrm{C} 18$ column that was pre-equilibrated with 95:5 deionized water containing 0.2\% formic acid: acetonitrile. The column was eluted at $50 \mathrm{~mL} / \mathrm{min}$ with 95:5 deionized water containing 0.2\% formic acid: acetonitrile for $5 \mathrm{~min}$ then with a linear gradient of 5\% acetonitrile at $5 \mathrm{~min}$ to $95 \%$ acetonitrile at $35 \mathrm{~min}$. Fractions containing desired product were combined, frozen and lyophilized to give $85 \mathrm{mg}$ of 13 (78\% yield). ${ }^{1} \mathrm{H}$ NMR (400 MHz, DMSO- $\left.d 6\right) \delta 8.25(\mathrm{~d}, J=8.2$ $\mathrm{Hz}, 1 \mathrm{H}), 7.78(\mathrm{~d}, J=10.8 \mathrm{~Hz}, 1 \mathrm{H}), 7.27(\mathrm{~s}, 1 \mathrm{H}), 6.52(\mathrm{~s}, 1 \mathrm{H}), 5.42(\mathrm{~s}, 2 \mathrm{H}), 5.22(\mathrm{~s}, 2 \mathrm{H}), 4.87(\mathrm{t}, J$ $=5.4 \mathrm{~Hz}, 1 \mathrm{H}), 4.47-4.28(\mathrm{~m}, 2 \mathrm{H}), 3.56(\mathrm{q}, J=6.3 \mathrm{~Hz}, 2 \mathrm{H}), 3.33(\mathrm{~s}, 2 \mathrm{H}), 2.62(\mathrm{t}, J=6.6 \mathrm{~Hz}$, 2H), $2.48-2.44(\mathrm{~m}, 3 \mathrm{H}), 1.87$ (hept, $J=7.1, \mathrm{~Hz}, 2 \mathrm{H}), 0.88(\mathrm{t}, J=7.3 \mathrm{~Hz}, 3 \mathrm{H}) .{ }^{13} \mathrm{C}$ NMR $(101$ MHz, DMSO-d6) $\delta 172.44,163.07,160.58,156.69,152.16,149.97,148.66,148.53,145.48$, $140.06,128.18,128.16,127.28,127.07,126.61,126.54,123.59,119.09,112.56,112.35,96.77$, 72.36, 65.26, 60.83, 49.69, 34.38, 30.31, 28.78, 15.24, 15.20, 7.75. HRMS $(\mathrm{M}+\mathrm{H})^{+}$calcd. 471.1390, found 471.1393 .

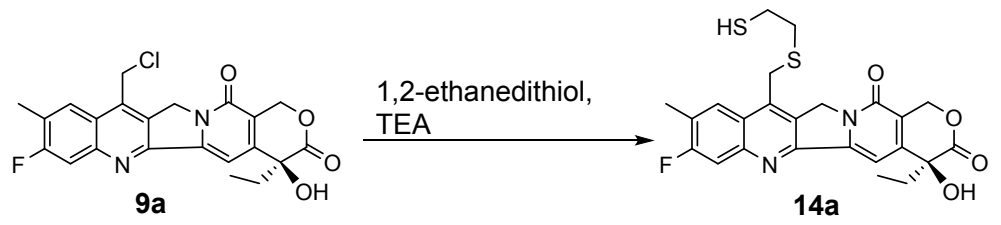


14a: Prepared similarly to 13 but using 1,2-ethanedithiol in place of 2-mercaptoethanol (47\% yield). MS (ESI): $(\mathrm{M}+\mathrm{H})^{+}$calcd. 487.1, found 487.3.

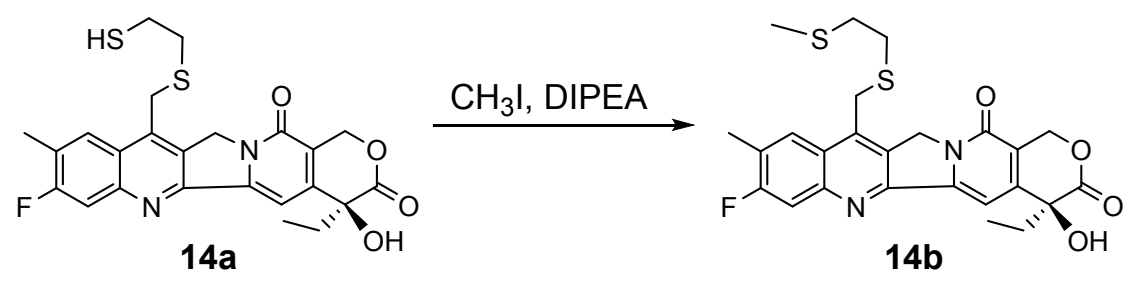

14b: Compound 14a (28 mg, $0.057 \mathrm{mmol})$ was dissolved in anhydrous THF $(1 \mathrm{~mL})$ to which was added $60 \% \mathrm{NaH}$ emulsion in mineral oil $(5 \mathrm{mg}, 2.1 \mathrm{mmol})$ with magnetic stirring. After 2 min, iodomethane $(20 \mu \mathrm{L}, 0.32 \mathrm{mmol})$ was added. After $20 \mathrm{~min}$ solvent was evaporated under vacuum and residue was taken up in anhydrous DMF $(1 \mathrm{~mL})$ then purified by medium pressure C18 chromatography. Column $100 \mathrm{~g} \mathrm{C} 18,50 \mathrm{~mL} / \mathrm{min}, 0.2 \%$ formic acid in deionized water with $5 \%$ acetonitrile from $0-5 \mathrm{~min}$ then a linear gradient of $5 \%-95 \%$ from $5 \mathrm{~min}-28 \mathrm{~min}$. fractions containing desired product were combined, frozen and lyophilized to give $15 \mathrm{mg}$ of $\mathbf{1 4 b}$ as a yellow solid (54\% yield). ${ }^{1} \mathrm{H}$ NMR (400 MHz, DMSO- $d 6$ ) $\delta 8.40-8.27$ (m, $\left.1 \mathrm{H}\right), 7.89$ (d, $J=$ $10.8 \mathrm{~Hz}, 1 \mathrm{H}), 7.31(\mathrm{~s}, 1 \mathrm{H}), 6.52(\mathrm{~s}, 1 \mathrm{H}), 5.43(\mathrm{~s}, 2 \mathrm{H}), 5.39$ (s, 1H), 5.32 (s, 1H), 4.57 - 4.39 (m, 2H), $2.84-2.69(\mathrm{~m}, 3 \mathrm{H}), 2.44(\mathrm{~m}, 1 \mathrm{H}), 2.07(\mathrm{~m}, 1 \mathrm{H}), 2.02(\mathrm{~s}, 3 \mathrm{H}), 1.87(\mathrm{~m}, 2 \mathrm{H}), 1.23(\mathrm{~s}, 1 \mathrm{H})$, $0.87(\mathrm{t}, J=7.3 \mathrm{~Hz}, 3 \mathrm{H})$. HRMS $(\mathrm{M}+\mathrm{H})^{+}$calcd. 501.1318; found 501.1322 .

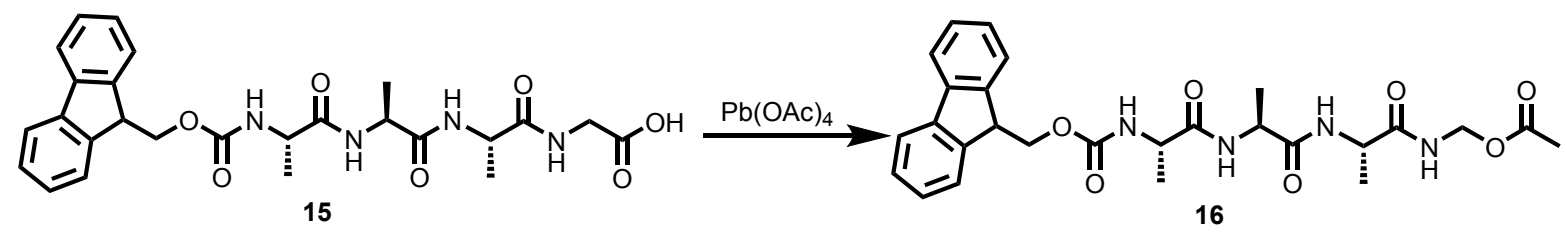

16: Compound 15 (2.5 g, $4.9 \mathrm{mmol})$ was dissolved in anhydrous DMF $(40 \mathrm{~mL})$ and magnetically stirred in a $100 \mathrm{~mL}$ flask as copper (II) acetate $(0.334 \mathrm{~g}, 1.84 \mathrm{mmol})$, acetic acid $(0.64 \mathrm{~mL}, 11.1$ $\mathrm{mmol})$, and lead tetraacetate $(2.5 \mathrm{~g}, 5.6 \mathrm{mmol})$ were added. The flask was heated in a $60{ }^{\circ} \mathrm{C}$ oil bath for $15 \mathrm{~min}$. The oil bath was removed and the reaction was allowed to cool to room temperature. The mixture was purified in two equal injections on a $350 \mathrm{~g}$ medium pressure $\mathrm{C} 18$ column that was equilibrated with 90:10 deionized water containing $0.3 \%$ formic acid:acetonitrile. The column was eluted at $100 \mathrm{~mL} / \mathrm{min}$ with $10 \%$ acetonitrile for $5 \mathrm{~min}$ then with a linear gradient of $10 \%$ acetonitrile from $5 \mathrm{~min}$ to $95 \%$ acetonitrile at $38 \mathrm{~min}$. Fractions containing 16 were combined, frozen and lyophilized to give $1.2 \mathrm{~g}$ of white semi-solid (62\% 
yield). ${ }^{1} \mathrm{H}$ NMR (400 MHz, DMSO-d6) $\delta 8.86(\mathrm{t}, J=6.9 \mathrm{~Hz}, 1 \mathrm{H}), 7.97(\mathrm{dd}, J=16.1,7.4 \mathrm{~Hz}$, 2H), $7.89(\mathrm{dt}, J=7.6,0.9 \mathrm{~Hz}, 2 \mathrm{H}), 7.72(\mathrm{t}, J=7.1 \mathrm{~Hz}, 2 \mathrm{H}), 7.53(\mathrm{~d}, J=7.5 \mathrm{~Hz}, 1 \mathrm{H}), 7.42(\mathrm{td}, J=$ 7.5, 1.2 Hz, 2H), $7.33(\mathrm{td}, J=7.5,1.2 \mathrm{~Hz}, 2 \mathrm{H}), 5.13-5.01(\mathrm{~m}, 2 \mathrm{H}), 4.30-4.17(\mathrm{~m}, 4 \mathrm{H}), 4.06$ (t, $J=7.3 \mathrm{~Hz}, 1 \mathrm{H}), 3.32(\mathrm{~s}, 1 \mathrm{H}), 1.99$ (s, 3H), 1.27 - 1.13 (m, 9H). MS (ESI): MS (M + Na) calcd. 547.2, found 547.5.

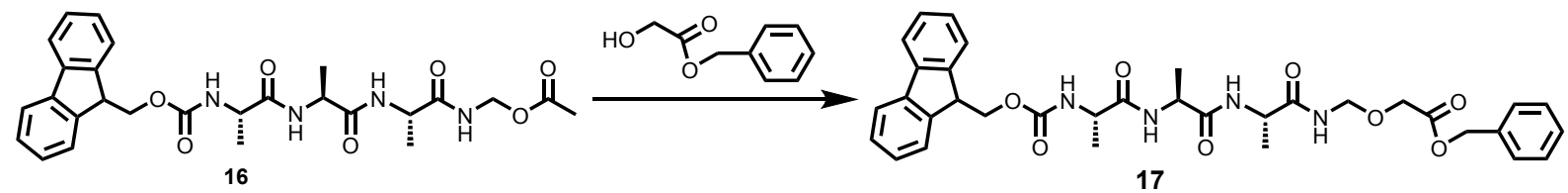

17: Compound 16 (142 mg, $0.27 \mathrm{mmol}$ ) and benzyl-2-hydroxyacetate (226 mg, $1.36 \mathrm{mmol})$ were suspended in a solution of $20 \%$ TFA in dichloromethane $(7 \mathrm{~mL})$ and magnetically stirred at room temperature for $30 \mathrm{~min}$. Solvent was rotary evaporated under vacuum and the residue was taken up in a minimum volume of DMF then purified on a $200 \mathrm{~g} \mathrm{C} 18$ medium pressure column that was pre-equilibrated with 90:10 deionized water containing $0.1 \%$ formic acid : acetonitrile. The column was then eluted at $60 \mathrm{~mL} / \mathrm{min}$ with $10 \%$ acetontrile for $5 \mathrm{~min}$ followed by a linear gradient of $10 \%$ acetonitrile from $5 \mathrm{~min}$ to $95 \%$ acetonitrile at $38 \mathrm{~min}$. Fractions containing desired product were combined, frozen and lyophilized to give $102 \mathrm{mg}$ of white solid $\mathbf{1 7}$ (59\% yield). MS (ESI): MS (M + Na) ${ }^{+}$calcd. 653.3, found 653.5.

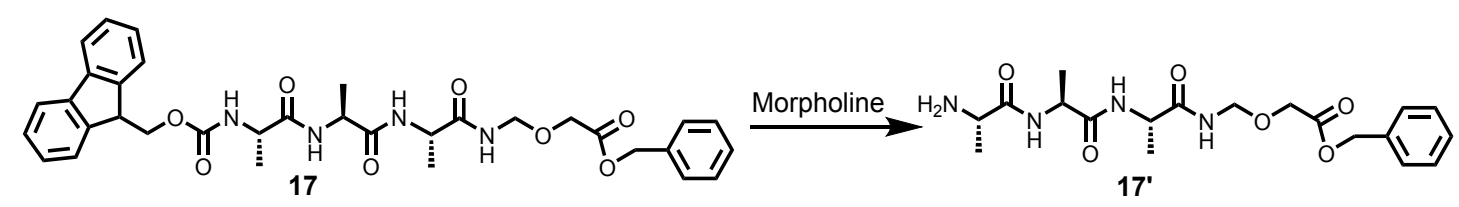

17': Compound 17 (100 mg, $0.16 \mathrm{mmol})$ was dissolved in DMF (4 mL) to which morpholine $(0.6 \mathrm{~mL}, 6.9 \mathrm{mmol})$ was added and magnetically stirred. After $1 \mathrm{~h}$ the reaction mixture was purified on a $200 \mathrm{~g} \mathrm{C} 18$ medium pressure column that was pre-equilibrated with 95:5 deionized water containing $0.1 \%$ formic acid : acetonitrile. The column was then eluted at $60 \mathrm{~mL} / \mathrm{min}$ with $5 \%$ acetontrile for $5 \mathrm{~min}$ followed by a linear gradient of $5 \%$ acetonitrile from $5 \mathrm{~min}$ to $70 \%$ acetonitrile at $38 \mathrm{~min}$. Fractions containing desired product were combined, frozen and lyophilized to give $50 \mathrm{mg}$ of white solid 17' (76 \% yield). MS (ESI): MS (M+ H) ${ }^{+}$calcd. 409.2, found 409.6. 


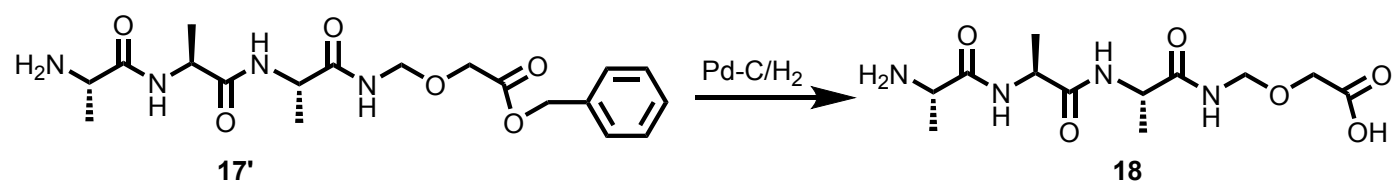

18: Compound 17' (50 mg, $0.12 \mathrm{mmol})$, dissolved in 5:95 deionized water: methanol (50 $\mathrm{mL})$ to which was added $10 \%$ palladium on carbon $(0.1 \mathrm{~g})$. The mixture was hydrogenated in a PARR shaker at $30 \mathrm{PSI}_{2}$ for $1 \mathrm{~h}$ then vacuum filtered through celite filter aid and solvent was removed from the filtrate by rotary evaporation under vacuum to give $35 \mathrm{mg}$ of desired product 18 as a thick oil (91\% yield). MS (ESI): MS (M + H) calcd. 319.2, found 319.3.<smiles>CCCC1=CC(=O)N(CCCCCC(=O)NC(C)C(=O)NC(C)C(=O)NC(C)C(=O)NCOCC(=O)O)C1=O</smiles>

20: Compound 19 (46 mg, $0.15 \mathrm{mmol}$ ) was dissolved in anhydrous DMF (2 mL) to which was added DIPEA $(0.1 \mathrm{~mL}, 0.31 \mathrm{mmol})$ and $18(30 \mathrm{mg}, 0.093 \mathrm{mmol})$. The reaction was magnetically stirred for 15 min then purified on a $50 \mathrm{~g} \mathrm{C} 18$ medium pressure column that was pre-equilibrated with 95:5 deionized water containing $0.1 \%$ formic acid : acetonitrile. The column was then eluted at $40 \mathrm{~mL} / \mathrm{min}$ with $5 \%$ acetontrile for $5 \mathrm{~min}$ followed by a linear gradient of $5 \%$ acetonitrile from $5 \mathrm{~min}$ to $90 \%$ acetonitrile at $38 \mathrm{~min}$. Fractions containing desired product were combined, frozen and lyophilized to give $30 \mathrm{mg}$ of white solid 20 (63\% yield). ${ }^{1} \mathrm{H}$ NMR (400 MHz, DMSO-d6) $\delta 12.16(\mathrm{~s}, 1 \mathrm{H}), 8.64-8.48(\mathrm{~m}, 1 \mathrm{H}), 7.97$ (dd, $J=7.3,3.2 \mathrm{~Hz}, 2 \mathrm{H}), 7.89$ (d, $J$ $=7.5 \mathrm{~Hz}, 1 \mathrm{H}), 7.00(\mathrm{~s}, 2 \mathrm{H}), 4.3-4.7(\mathrm{~m}, 4 \mathrm{H}), 4.21(\mathrm{dt}, J=10.3,7.2 \mathrm{~Hz}, 4 \mathrm{H}), 3.55(\mathrm{t}, J=6.4 \mathrm{~Hz}$, 2H), $3.37(\mathrm{t}, J=7.1 \mathrm{~Hz}, 2 \mathrm{H}), 2.41(\mathrm{t}, J=6.4 \mathrm{~Hz}, 2 \mathrm{H}), 2.08$ (t, $J=7.4 \mathrm{~Hz}, 2 \mathrm{H}), 1.47$ (p, $J=7.2$ $\mathrm{Hz}, 4 \mathrm{H}), 1.27-1.10(\mathrm{~m}, 6 \mathrm{H})$. MS (ESI): MS (M - H)ำ calcd. 510.2, found 510.1.

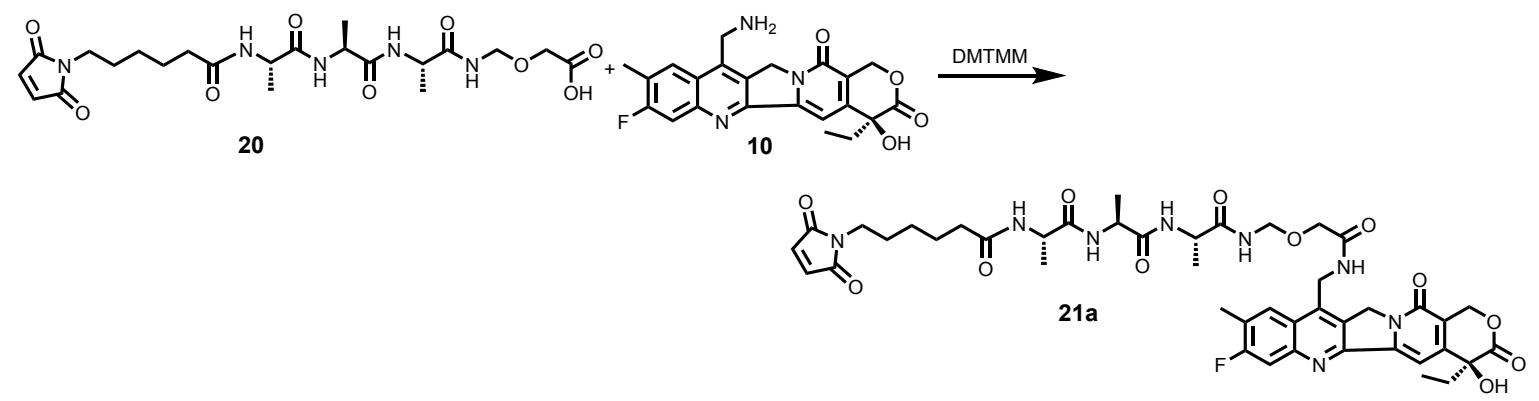


21a: Compound 10 (20 mg, $0.049 \mathrm{mmol})$ and DMTMM (18 $\mathrm{mg}, 0.065 \mathrm{mmol})$ in $85: 15$ DMF:deionized water $(0.8 \mathrm{~mL})$ were magnetically stirred as $20(35 \mathrm{mg}, 0.068 \mathrm{mmol})$ and TEA $(0.04 \mathrm{~mL}, 0.28 \mathrm{mmol})$ were sequentially added. After $1 \mathrm{~h}$ the reaction mixture was loaded onto a $50 \mathrm{~g}$ medium pressure silica column that was equilibrated with dichloromethane and run at 30 $\mathrm{mL} / \mathrm{min}$ with dichloromethane using a linear gradient of $0 \%$ to $100 \%$ of $20 \%$ methanol in dichloromethane over $40 \mathrm{~min}$. Fractions containing pure product were combined and solvent was removed by rotary evaporation under vacuum to give $16 \mathrm{mg}$ of a yellow solid $\mathbf{2 1 a}$ (36\% yield). ${ }^{1} \mathrm{H}$ NMR (400 MHz, DMSO-d6) $\delta 0.88(\mathrm{t}, J=7.3 \mathrm{~Hz}, 3 \mathrm{H}), 1.11-1.23(\mathrm{~m}, 15 \mathrm{H}), 1.46(\mathrm{p}$, $J=7.3 \mathrm{~Hz}, 5 \mathrm{H}), 1.79-1.95(\mathrm{~m}, 2 \mathrm{H}), 2.07(\mathrm{t}, J=7.4 \mathrm{~Hz}, 2 \mathrm{H}), 3.04-3.16(\mathrm{~m}, 2 \mathrm{H}), 3.88(\mathrm{~s}, 2 \mathrm{H})$, $4.18(\mathrm{dd}, J=7.1,11.0 \mathrm{~Hz}, 2 \mathrm{H}), 4.50-4.65(\mathrm{~m}, 2 \mathrm{H}), 4.86(\mathrm{~d}, J=5.9 \mathrm{~Hz}, 2 \mathrm{H}), 5.44$ (s, 2H), 5.49 $(\mathrm{s}, 2 \mathrm{H}), 6.53(\mathrm{~s}, 1 \mathrm{H}), 7.00(\mathrm{~s}, 2 \mathrm{H}), 7.32(\mathrm{~s}, 1 \mathrm{H}), 7.91(\mathrm{~d}, J=10.0 \mathrm{~Hz}, 1 \mathrm{H}), 7.97(\mathrm{~d}, J=7.0 \mathrm{~Hz}$, $2 \mathrm{H}), 8.43(\mathrm{~d}, J=8.3 \mathrm{~Hz}, 1 \mathrm{H}), 8.65(\mathrm{t}, J=6.6 \mathrm{~Hz}, 1 \mathrm{H}), 8.73(\mathrm{t}, J=5.9 \mathrm{~Hz}, 1 \mathrm{H}) .{ }^{13} \mathrm{C}$ NMR $(101$ MHz, DMSO-d6) $\delta 180.20,173.96,172.96,172.89,172.56,172.36,171.54,170.03,163.99$, 157.27, 156.21, 152.90, 150.48, 145.85, 139.87, 134.92, 129.28, 128.06, 124.24, 119.65, 97.28, 72.84, 70.18, 67.29, 65.74, 50.53, 48.81, 48.68, 48.60, 46.26, 41.01, 37.44, 35.26, 30.71, 28.24, 26.23, 25.09, 18.33, 18.24, 18.18, 15.77, 15.74, 9.12, 8.21. HRMS $(\mathrm{M}+\mathrm{H})^{+}$calcd. 903.3688, found 903.3676 .

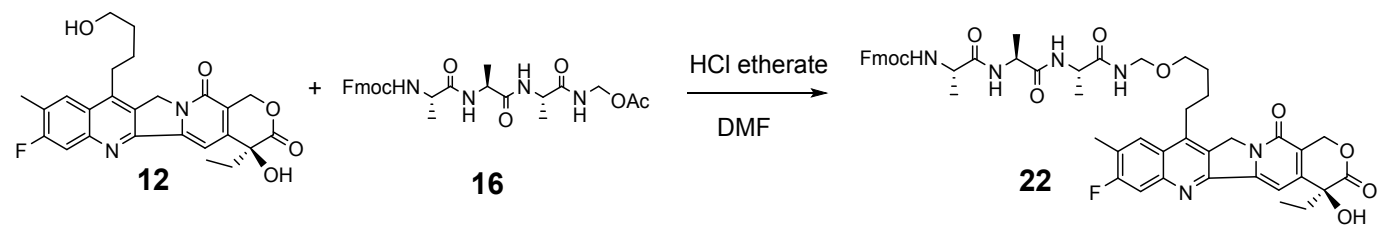

22: To a stirring solution of 12 (58 $\mathrm{mg}, 0.106 \mathrm{mmol})$ and compound 16 (55.8 $\mathrm{mg}, 0.106 \mathrm{mmol})$ in anhydrous DMF $(1.5 \mathrm{~mL})$ was added $\mathrm{HCl}$ etherate $(2 \mathrm{M} \mathrm{HCl}$ diethyl ether solution, $64 \mu \mathrm{L}$, $0.128 \mathrm{mmol}$ ). After stirring $22 \mathrm{~h}$ at room temperature, the reaction solution was stripped under reduced pressure $\left(35^{\circ} \mathrm{C}\right.$ heating bath). The residue was purified by reverse phase HPLC (30 g C18 column, $\mathrm{CH}_{3} \mathrm{CN} / \mathrm{H}_{2} \mathrm{O}, 25 \% \mathrm{CH}_{3} \mathrm{CN}$ for 3 min then to $90 \% \mathrm{CH}_{3} \mathrm{CN}$ in 12 min then $90 \%$ $\mathrm{CH}_{3} \mathrm{CN}$ for $3 \mathrm{~min}$ ) to give compound 22 as a white solid (47 mg, yield 48\%). MS (ESI): (M+ $\mathrm{H})^{+}$calcd. 917.4, found 917.6.
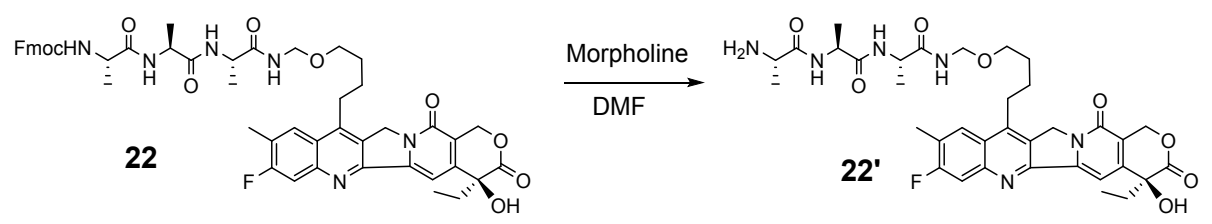
22': Compound 22 (57 mg, $0.062 \mathrm{mmol})$ was dissolved in anhydrous DMF $(1 \mathrm{~mL})$ and magnetically stirred as morpholine $(0.027 \mathrm{~mL}, 0.31 \mathrm{mmol})$ was added. After $1 \mathrm{~h}$ the reaction mixture was directly loaded on a $100 \mathrm{~g} \mathrm{C} 18$ cartridge $5: 95 \mathrm{CH}_{3} \mathrm{CN} / \mathrm{H}_{2} \mathrm{O}$, run at $50 \mathrm{~mL} / \mathrm{min} 5 \%$ $\mathrm{CH}_{3} \mathrm{CN}$ for 3 min then with a linear gradient of $5-90 \% \mathrm{CH}_{3} \mathrm{CN}$ from $3-23$ min. Fractions containing desired product were combined, frozen and lyophilized to give $24 \mathrm{mg}$ ( $83 \%$ yield) of 22' as a yellow solid. MS (ESI): MS $(\mathrm{M}+\mathrm{H})^{+}$calcd. 695.3, found 695.5.

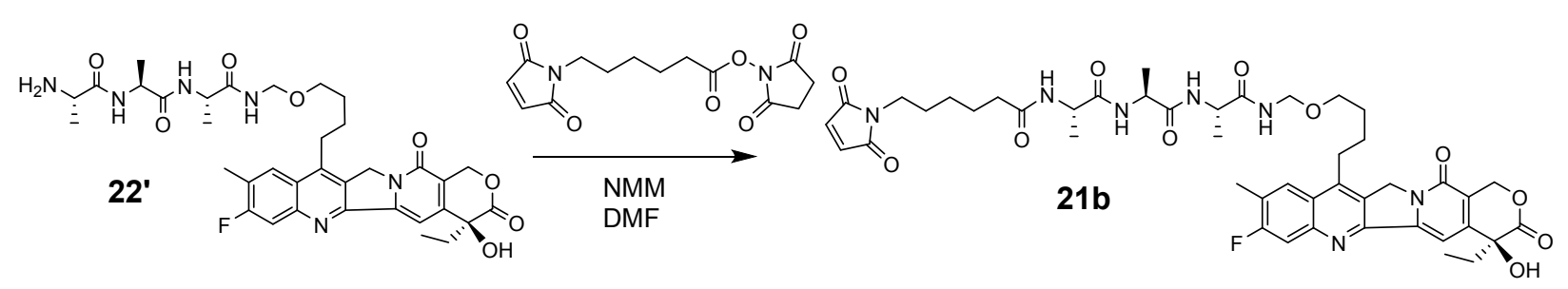

21b: To a solution of compound 22' (18 $\mathrm{mg}, 0.026 \mathrm{mmol})$ in anhydrous DMF $(0.3 \mathrm{~mL})$ was added 5-maleimidohexanoic acid $N$-hydroxysuccinimide ester (12 mg, $0.039 \mathrm{mmol})$ and $\mathrm{N}$ methyl morpholine $(3.1 \mu \mathrm{L}, 0.028 \mathrm{mmol})$. After stirring at room temperature for $4 \mathrm{~h}$ the reaction solution was stripped under reduced pressure. The residue was purified by reverse phase HPLC (30 g C18 column, eluted with $\mathrm{CH}_{3} \mathrm{CN} / \mathrm{H}_{2} \mathrm{O}, 20 \% \mathrm{CH}_{3} \mathrm{CN}$ for 3 min, then $20 \%$ to $90 \% \mathrm{CH}_{3} \mathrm{CN}$ in $12 \mathrm{~min}$ then $90 \% \mathrm{CH}_{3} \mathrm{CN}$ for $3 \mathrm{~min}$ ) to give product $\mathbf{2 1 \mathrm { b }}$ as a white solid (11.9 $\mathrm{mg}$, yield $51 \%) .{ }^{1} \mathrm{H}$ NMR (400 MHz, DMSO- $\left.d_{6}\right) \delta 8.45(\mathrm{t}, J=6.7 \mathrm{~Hz}, 1 \mathrm{H}), 8.11(\mathrm{~d}, J=8.2 \mathrm{~Hz}, 1 \mathrm{H}), 7.90$ (t, $J=7.5 \mathrm{~Hz}, 2 \mathrm{H}), 7.78(\mathrm{dd}, J=15.2,9.1 \mathrm{~Hz}, 2 \mathrm{H}), 7.22(\mathrm{~s}, 1 \mathrm{H}), 6.92(\mathrm{~s}, 2 \mathrm{H}), 6.45(\mathrm{~s}, 1 \mathrm{H}), 5.36$ (s, 2H), 5.17 (s, 2H), $4.54-4.38(\mathrm{~m}, 2 \mathrm{H}), 4.15-4.09(\mathrm{~m}, 2 \mathrm{H}), 3.38-3.33(\mathrm{~m}, 1 \mathrm{H}), 3.32-3.21$ (m, 1H), $3.15-3.06$ (m, 1H), $2.50-2.42$ (m, 3H), 1.99 (t, $J=7.4 \mathrm{~Hz}, 2 \mathrm{H}), 1.79$ (h, $J=7.0 \mathrm{~Hz}$, 2H), $1.67-1.55$ (m, 6H), 1.38 (p, $J=7.4 \mathrm{~Hz}, 5 \mathrm{H}), 1.15-1.04$ (m, 12H), 0.81 (t, $J=7.4 \mathrm{~Hz}$, $3 \mathrm{H}) .{ }^{13} \mathrm{C}$ NMR (101 MHz, DMSO- $\left.d_{6}\right) \delta 174.54,173.86,171.34,171.26,170.84,170.79,170.47$, $170.15,161.42$, 158.95, 155.71, 155.16, 150.43, 148.38, 146.97, 146.80, 144.22, 142.23, 129.03, $126.25,125.69,125.48,124.98,124.50,122.77,122.48,117.29,111.01,110.78,95.09,70.75$, $70.67,67.55,65.17,63.64,48.03,46.55,33.20,28.68,27.46,26.96,25.04,24.55,24.05,23.06$, 22.84, 16.39, 16.14, 13.54, 6.13, 5.98; HRMS $(\mathrm{M}+\mathrm{H})^{+}$calcd. 888.3943, found 888.3966. 

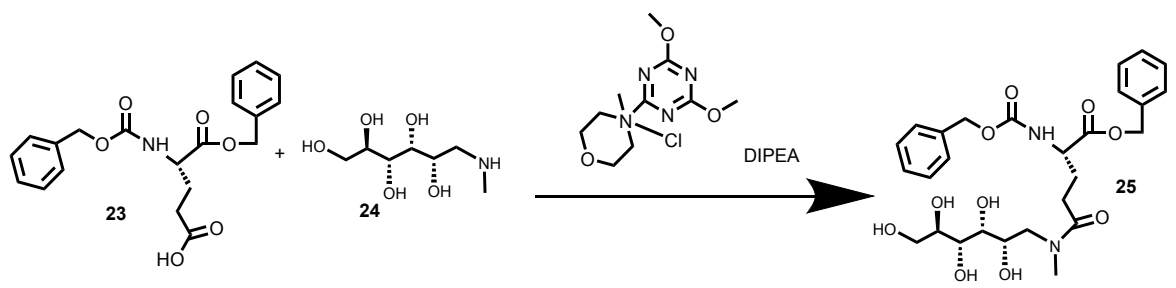

25: Z-L-Glu-OBn 23 (5 g, $13.46 \mathrm{mmol}$ ) and $N$-Methyl- $D$-Glucamine 24 (3.94 g, $20.19 \mathrm{mmol}$ ) were weighed into a $200 \mathrm{~mL}$ flask to which was added DMF $(50 \mathrm{~mL})$ and magnetically stirred then DIPEA $(2.351 \mathrm{ml}, 13.46 \mathrm{mmol})$ was added followed by as a suspension of DMTMM (5.22 $\mathrm{g}, 18.85 \mathrm{mmol})$ in DMF $(30 \mathrm{~mL})$ and deionized water $(10 \mathrm{~mL})$. After $2 \mathrm{~h}$ the reaction was purified in three equal runs, each loaded on a $450 \mathrm{~g} \mathrm{C} 18$ cartridge that was pre-equilibrated with 95:5 deionized water : acetonitrile. The column was eluted at $100 \mathrm{~mL} / \mathrm{min}$ with 95:5 Deionized water:acetonitrile for $5 \mathrm{~min}$ then with a linear gradient of $5 \%$ acetonitrile to $95 \%$ acetonitirle over $38 \mathrm{~min}$. Fractions containing pure desired product were pooled and solvent was removed by rotary evaporation under vacuum. Methanol $(100 \mathrm{~mL})$ was added and evaporated 2 times to give $5 \mathrm{~g}$ of desired 25 as a thick colorless oil (68\% yield). MS (ESI): MS (M+ H) calcd. 549.2, found 549.3, MS (ESI): (M - H)- calcd 547.2, found 547.2.

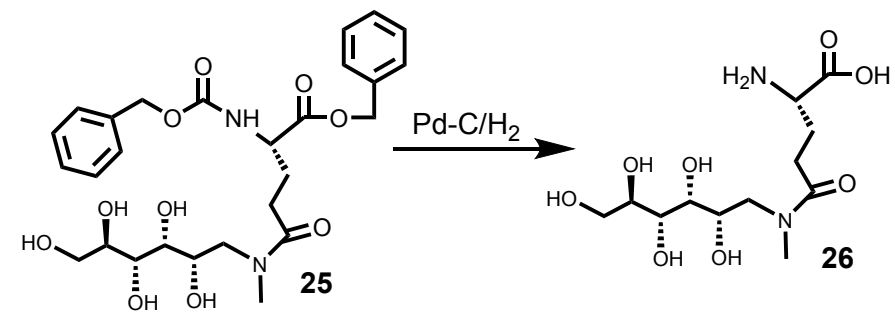

26: Compound 25 (5 g, $9.1 \mathrm{mmol})$ was suspended in 95:5 methanol:deionized water $(100 \mathrm{~mL})$ in a $250 \mathrm{~mL}$ PARR shaker flask to which was added 10\% Pd-C (0.13 g, $1.222 \mathrm{mmol})$ and hydrogenated at $30 \mathrm{PSI}_{2}$ for $45 \mathrm{~min}$, adding $\mathrm{H}_{2}$ periodically to reestablish pressure. The solution was vacuum filtered through celite filter aid. The clear colorless filtrate was concentrated under by rotary evaporation under vacuum then left under vacuum over night to give 26 as a white solid (2.8 g, 94\% yield). ${ }^{1} \mathrm{H}$ NMR (400 MHz, DMSO- $\left.d 6\right) \delta 4.09-3.98$ (m, $1 \mathrm{H}), 3.84(\mathrm{dt}, J=6.1,3.1 \mathrm{~Hz}, 1 \mathrm{H}), 3.79$ (d, $J=6.0 \mathrm{~Hz}, 1 \mathrm{H}), 3.75(\mathrm{ddd}, J=7.5,4.2,2.3 \mathrm{~Hz}, 1 \mathrm{H})$, $3.72-3.59(\mathrm{~m}, 3 \mathrm{H}), 3.56-3.51(\mathrm{~m}, 1 \mathrm{H}), 3.48(\mathrm{dd}, J=15.0,3.6 \mathrm{~Hz}, 1 \mathrm{H}), 3.13(\mathrm{~s}, 2 \mathrm{H}), 2.97$ (s, $1 \mathrm{H}), 2.78-2.49(\mathrm{~m}, 2 \mathrm{H}), 2.22-2.06(\mathrm{~m}, 2 \mathrm{H})$. MS (ESI): MS (M - H)- calcd. 323.1, found 323.4 . 


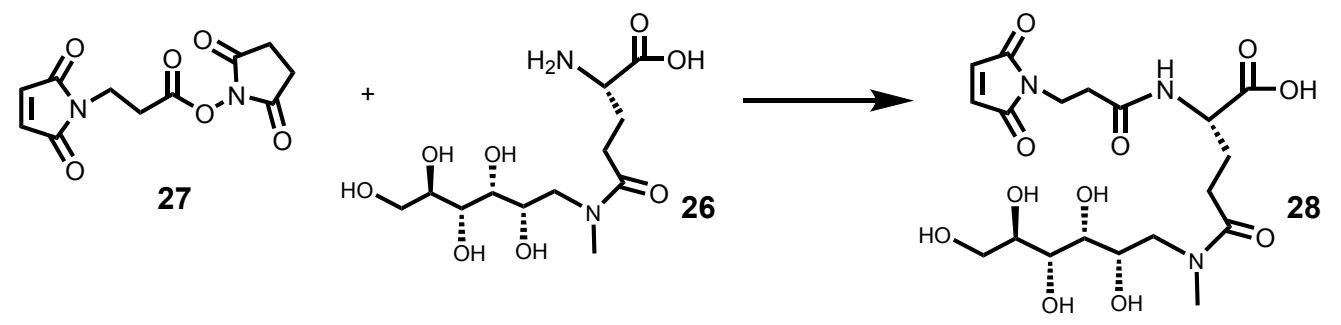

28: Compound 27 (1.4, $5.3 \mathrm{mmol})$ was added to a magnetically stirred solution of $\mathbf{2 6}$ (1.8 g, 5.5 $\mathrm{mmol})$ in DMF $(10 \mathrm{~mL})$ and DIPEA $(1.1 \mathrm{~mL}, \mathrm{mmol})$. After stirring for $15 \mathrm{~min}$ the reaction was injected onto a medium pressure $350 \mathrm{~g} \mathrm{C18}$ column that was pre-equilibrated with 98:2 deionized water containing $0.1 \%$ formic acid : acetonitrile. The column was eluted at 100 $\mathrm{mL} / \mathrm{min}$ at $2 \%$ acetonitrile for $5 \mathrm{~min}$ then with a linear gradient of $2 \%$ acetonitrile at $5 \mathrm{~min}$ to $60 \%$ acetonitrile at $35 \mathrm{~min}$ detecting at 214 and $306 \mathrm{~nm}$. Fractions containing pure product were combined, frozen and lyophilized to give $1.4 \mathrm{~g}$ of $\mathbf{2 8}$ as a white solid (55\% yield). ${ }^{1} \mathrm{H}$ NMR (400 MHz, DMSO-d6) $\delta 8.33(\mathrm{dd}, J=9.2,7.7 \mathrm{~Hz}, 1 \mathrm{H}), 7.08(\mathrm{~d}, J=1.1 \mathrm{~Hz}, 2 \mathrm{H}), 4.24$ (qd, $J=8.8,4.8$ $\mathrm{Hz}, 1 \mathrm{H}), 3.86(\mathrm{dt}, J=8.2,4.0 \mathrm{~Hz}, 1 \mathrm{H}), 3.76-3.63(\mathrm{~m}, 4 \mathrm{H}), 3.62-3.43(\mathrm{~m}, 4 \mathrm{H}), 3.41-3.29$ (m, 1H), $3.08(\mathrm{~s}, 2 \mathrm{H}), 2.91(\mathrm{~s}, 2 \mathrm{H}), 2.61$ (q, $J=1.8 \mathrm{~Hz}, 1 \mathrm{H}), 2.40(\mathrm{dd}, J=10.0,6.4 \mathrm{~Hz}, 1 \mathrm{H}), 2.02$ $(\operatorname{tdd}, J=12.6,10.3,9.1,5.8 \mathrm{~Hz}, 1 \mathrm{H}), 1.93-1.76(\mathrm{~m}, 1 \mathrm{H})$. MS (ESI): MS (M + H) ${ }^{+}$calcd. 476.2, found 476.4 .

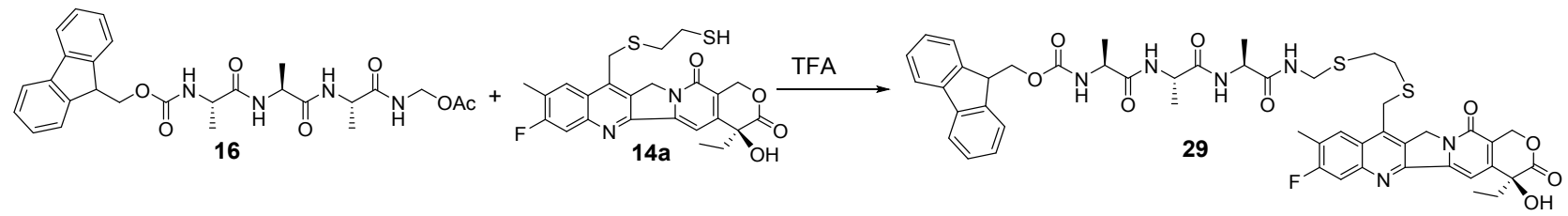

29: Compound 16 (30 mg, 0. 057 mmol) and 14a (50 mg, $0.1 \mathrm{mmol})$ were suspended in a solution of $20 \%$ TFA in dichloromethane $(10 \mathrm{~mL})$ and magnetically stirred at room temperature for $30 \mathrm{~min}$. Solvent was rotary evaporated under vacuum and the residue was taken up in a minimum volume of DMF then purified on a $100 \mathrm{~g} \mathrm{C18}$ medium pressure column that was preequilibrated with 90:10 deionized water containing 0.1\% formic acid : acetonitrile. The column was then eluted at $30 \mathrm{~mL} / \mathrm{min}$ with $10 \%$ acetontrile for $5 \mathrm{~min}$ followed by a linear gradient of 10\% acetonitrile from $5 \mathrm{~min}$ to $95 \%$ acetonitrile at $38 \mathrm{~min}$. Fractions containing desired product were combined, frozen and lyophilized to give $31 \mathrm{mg}$ of white solid 29 (56\% yield). MS (ESI): $\mathrm{MS}(\mathrm{M}+\mathrm{Na})^{+}$calcd. 973.3, found 973.7. 


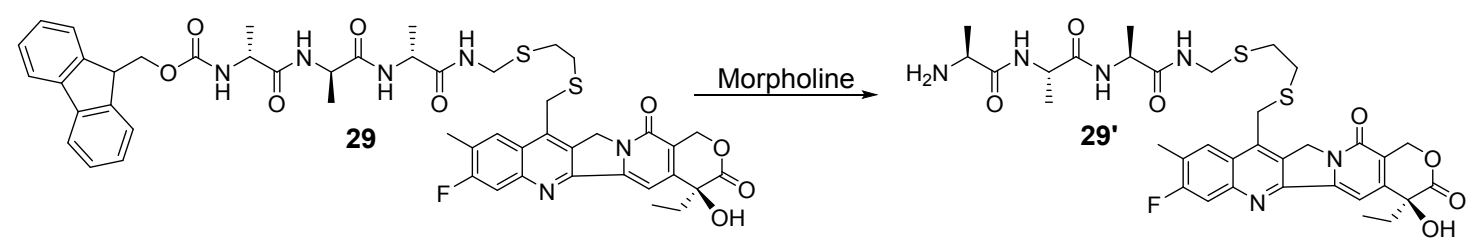

29': Compound 29 (28 mg, $0.029 \mathrm{mmol})$ was dissolved in anhydrous DMF (0.8 mL) and magnetically stirred as morpholine $(0.2 \mathrm{~mL}, 2.32 \mathrm{mmol})$ was added. After $1 \mathrm{~h}$ the reaction mixture was directly loaded on a $100 \mathrm{~g} \mathrm{C} 18$ cartridge $25: 75 \mathrm{CH}_{3} \mathrm{CN} / \mathrm{H}_{2} \mathrm{O}$, run at $50 \mathrm{~mL} / \mathrm{min} 25 \%$ $\mathrm{CH}_{3} \mathrm{CN}$ for $3 \mathrm{~min}$ then with a linear gradient to $90 \% \mathrm{CH}_{3} \mathrm{CN}$ from $3-23$ min. Fractions containing desired product were combined, frozen and lyophilized to give $18 \mathrm{mg}$ ( $83 \%$ yield) of 29' as a yellow solid. ' $\mathrm{H}$ NMR (400 MHz, DMSO-d6) $\delta 8.52(\mathrm{t}, J=6.3 \mathrm{~Hz}, 1 \mathrm{H}), 8.31(\mathrm{~d}, J=8.3$ $\mathrm{Hz}, 1 \mathrm{H}), 8.11(\mathrm{~d}, J=7.4 \mathrm{~Hz}, 2 \mathrm{H}), 7.87(\mathrm{t}, J=9.1 \mathrm{~Hz}, 2 \mathrm{H}), 7.69(\mathrm{~d}, J=7.5 \mathrm{~Hz}, 1 \mathrm{H}), 7.37(\mathrm{t}, J=$ $7.4 \mathrm{~Hz}, 1 \mathrm{H}), 7.31(\mathrm{t}, J=3.7 \mathrm{~Hz}, 2 \mathrm{H}), 5.43(\mathrm{~s}, 2 \mathrm{H}), 5.31(\mathrm{~s}, 2 \mathrm{H}), 4.47(\mathrm{~d}, J=2.6 \mathrm{~Hz}, 2 \mathrm{H}), 4.32-$ 4.09 (m, 4H), 3.69 (t, $J=4.6 \mathrm{~Hz}, 2 \mathrm{H}), 3.36$ (q, $J=6.9 \mathrm{~Hz}, 1 \mathrm{H}), 2.84$ (s, 4H), $2.61-2.54$ (m, $3 \mathrm{H}), 2.46-2.42(\mathrm{~m}, 4 \mathrm{H}), 1.94-1.75(\mathrm{~m}, 2 \mathrm{H}), 1.17$ (dd, $J=7.2,3.4 \mathrm{~Hz}, 6 \mathrm{H}), 1.12(\mathrm{~d}, J=6.8 \mathrm{~Hz}$, $3 \mathrm{H}), 0.87(\mathrm{t}, J=7.3 \mathrm{~Hz}, 3 \mathrm{H})$. MS (ESI): MS (M+H) ${ }^{+}$calcd. 729.3, found 729.4.
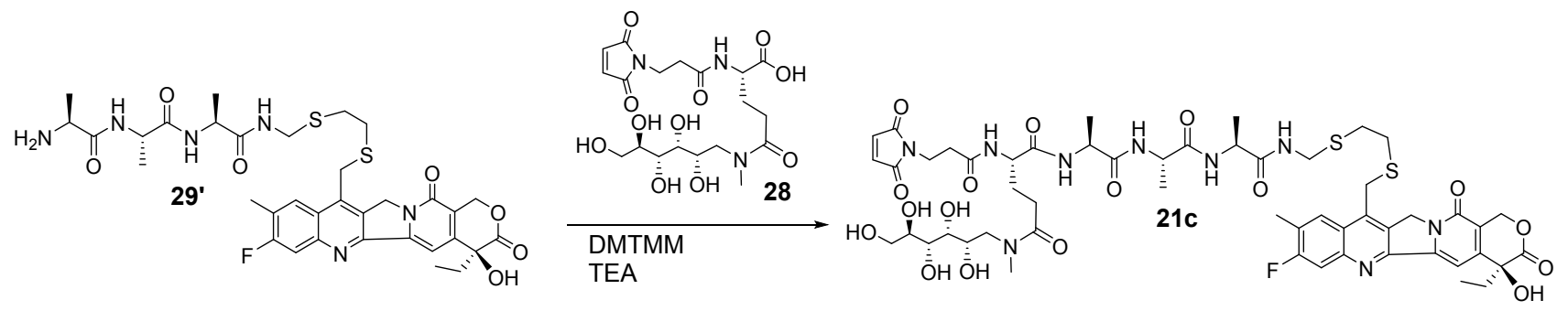

21c: Compound 29' (16 mg, $0.02 \mathrm{mmol})$ was dissolved in 84:16 DMF:deionized water $(0.5 \mathrm{~mL})$ to which DMTMM (15 mg, $0.054 \mathrm{mmol})$, TEA ( $0.02 \mathrm{~mL}, 0.14 \mathrm{mmol})$ and 28 (20 mg, 0.042 mmol) were quickly added and magnetically stirred. After $35 \mathrm{~min}$ the reaction mixture was loaded on a $100 \mathrm{~g}$ silica cartridge preequilibrated with dichloromethane then run at $35 \mathrm{~mL} / \mathrm{min}$ with a linear gradient over $30 \mathrm{~min}$ from $0 \%$ to $100 \%$ of 40:60 methanol:dichloromethane. Fractions containing desired product were combined and solvent was evaporated under vacuum to give $7 \mathrm{mg}$ of 21c (29\% yield) as a thick oil. ${ }^{1} \mathrm{H}$ NMR (400 MHz, DMSO-d6) $\delta 7.86-7.83$ (m, 1H), $7.71(\mathrm{~s}, 1 \mathrm{H}), 7.69(\mathrm{~d}, J=1.1 \mathrm{~Hz}, 1 \mathrm{H}), 7.66(\mathrm{~d}, J=8.2 \mathrm{~Hz}, 1 \mathrm{H}), 7.51-7.47(\mathrm{~m}, 2 \mathrm{H}), 7.28$ (t, $J=1.0 \mathrm{~Hz}, 1 \mathrm{H}), 6.61(\mathrm{~s}, 2 \mathrm{H}), 5.59-5.53(\mathrm{~m}, 1 \mathrm{H}), 5.40(\mathrm{dd}, J=3.3,1.1 \mathrm{~Hz}, 2 \mathrm{H}), 5.29-5.26(\mathrm{~m}$, 
2H), $4.72(\mathrm{~s}, 2 \mathrm{H}), 4.52-4.46(\mathrm{~m}, 1 \mathrm{H}), 4.38(\mathrm{~s}, 1 \mathrm{H}), 4.35$ (dd, $J=3.5,1.8 \mathrm{~Hz}, 2 \mathrm{H}), 4.28-4.22(\mathrm{~m}$, 2H), $4.21-4.13(\mathrm{~m}, 2 \mathrm{H}), 3.74(\mathrm{t}, J=6.5 \mathrm{~Hz}, 2 \mathrm{H}), 3.70(\mathrm{ddd}, J=11.9,5.7,4.8 \mathrm{~Hz}, 1 \mathrm{H}), 3.60-$ $3.51(\mathrm{~m}, 2 \mathrm{H}), 3.44(\mathrm{dd}, J=11.9,4.9 \mathrm{~Hz}, 1 \mathrm{H}), 3.3($ broad s, $8 \mathrm{H}), 3.20(\mathrm{dd}, J=4.7,3.7 \mathrm{~Hz}, 2 \mathrm{H})$, $2.91(\mathrm{~s}, 3 \mathrm{H}), 2.89$ (s, 3H), 2.56 (td, $J=6.4,1.7 \mathrm{~Hz}, 2 \mathrm{H}), 2.31(\mathrm{~s}, 3), 2.37-2.21(\mathrm{~m}, 2 \mathrm{H}), 2.07-$ $1.82(\mathrm{~m}, 3 \mathrm{H}), 1.72(\mathrm{dq}, J=13.7,8.1 \mathrm{~Hz}, 1 \mathrm{H}), 1.53(\mathrm{~d}, J=5.5 \mathrm{~Hz}, 6 \mathrm{H}), 1.45(\mathrm{~d}, J=5.9 \mathrm{~Hz}, 3 \mathrm{H})$, $0.86(\mathrm{t}, J=8.0 \mathrm{~Hz}, 3 \mathrm{H}) .{ }^{13} \mathrm{C}$ NMR $(101 \mathrm{MHz}$, DMSO- $d 6) \delta 174.75,174.58,172.85,172.75$, $172.45,171.62$, 171.37, 169.30, 163.44, 160.52, 157.18, 149.96, 148.73, 147.39, 147.32, 142.26, $132.98,131.74,127.54,127.38,127.24$. 126.88, 124.90, 124.84, 124.34, 122.88, 118.32, 116.83, $116.67,97.97,74.87,73.80,72.41,72.34,69.44,65.10,62.94,53.02,50.02,49.92,49.62,48.46$, $45.53,42.38,40.85,35.32,35.13,34.00,32.31,32.24,30.20,26.63,20.49,17.81,17.71,17.61$, 7.68. $\operatorname{HRMS}(\mathrm{M}+\mathrm{H})^{+}$calcd. 1186.4237, found 1186.4220 . 


\section{General method for the preparation of ADCs (Example mAb $\left.b_{E}-21 a\right)$ :}

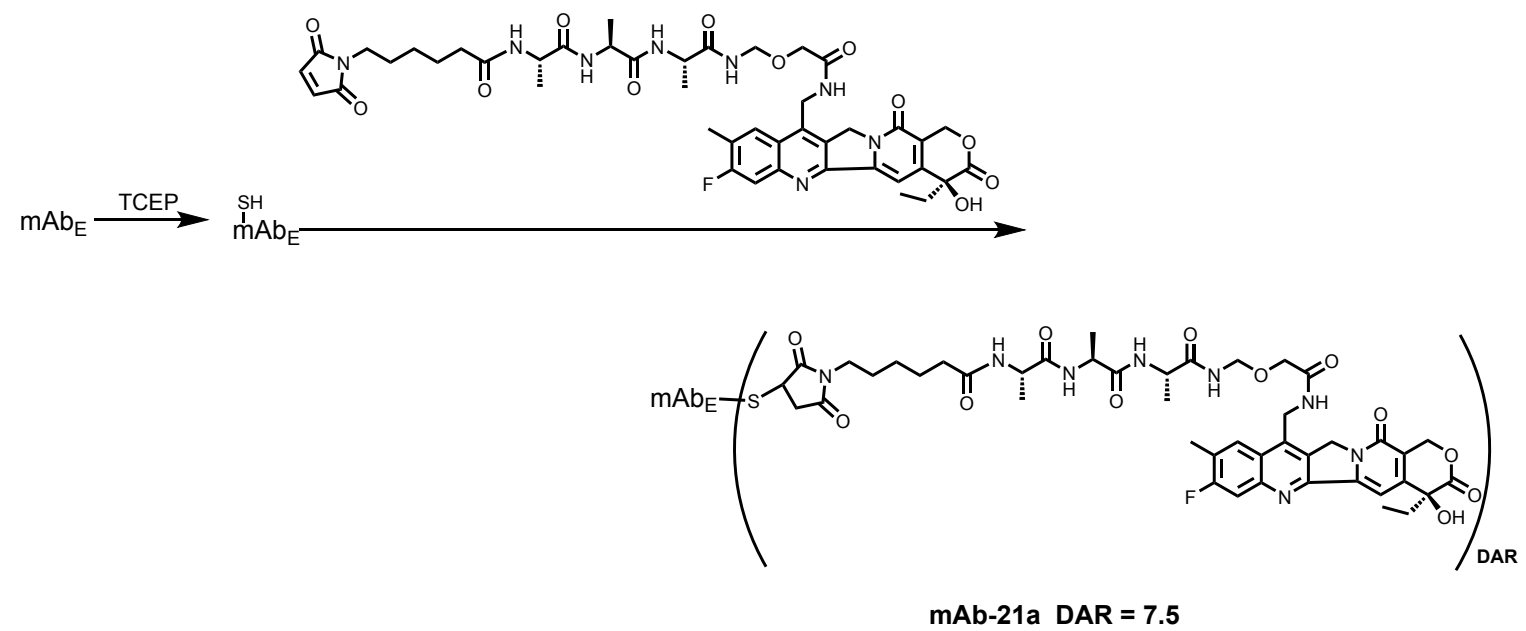

The IgG1 humanized anti-epidermal growth factor (anti-EGFR), and anti-folate receptor (anti$\mathrm{FR} \alpha$ ) antibodies and the chimeric antibody(chKTI), that binds to Kunitz soybean trypsin inhibitor, were generated at ImmunoGen. Conjugation of antibodies to maleimide-bearing payloads were performed as described for the preparation of $\mathbf{m} \mathbf{A b}_{\mathbf{E}} \mathbf{- 2 1 a}$. The conjugation procedure has some batch to batch variability, for example two couplings of $\mathrm{mAb} \mathrm{b}_{\mathrm{E}}$ to $\mathbf{2 1 d}$ were performed, with one giving a DAR of 7.5 and the other a DAR of 7.6. Also some payloads or antibodies did not conjugate as well as others. Therefore, the amount of ADC used in an experiment is based on the amount of payload delivered unless stated otherwise.

$\mathbf{m A b} \mathbf{b}_{\mathbf{E}}-\mathbf{2 1 a}$ : Anti-huEGFR at $5 \mathrm{mg} / \mathrm{ml}$ was treated with 7.0 equivalents of TCEP in $50 \mathrm{mM}$ EPPS $\mathrm{pH} 7.4,5 \mathrm{mM}$ EDTA at $37^{\circ} \mathrm{C}$ for $1-1.5 \mathrm{~h}$. The mixture was then cooled to room temperature. The conjugation reaction between antibody and the payload was performed at $2 \mathrm{mg} / \mathrm{ml}$ by adding 15 20 equivalents of 21 a dissolved in buffer (50 mM EPPS, pH7.4) containing 20\% DMSO, and spinning on a tube rotator for 1.5-2.5 $\mathrm{h}$ at room temperature. The reaction mixture was immediately purified into formulation buffer $(10 \mathrm{mM}$ acetate, $9 \%$ sucrose, $0.01 \%$ Tween-20, $\mathrm{pH}$ 5.0) using a NAP SEC column (Illustra Sephedex G-25, GE Healthcare). The resulting conjugate had DAR of 7.5, and was $99 \%$ monomeric measured by SEC.

Biophysical evaluations for inter-chain high DAR conjugates were determined, including conjugate concentration, yield, DAR, free drug, percent monomer and DAR distribution. The 
conjugate concentration was determined to have a final protein concentration of $4.5 \mathrm{mg} / \mathrm{mL}$ (via UV-Vis using extinction coefficient $\varepsilon_{280}=205,520 \mathrm{M}^{-1} \mathrm{~cm}^{-1}$ ), DAR 7.5 (via UV-Vis using extinction coefficients $\varepsilon_{280}=10,764 \mathrm{M}^{-1} \mathrm{~cm}^{-1}, \varepsilon_{370}=20,982 \mathrm{M}^{-1} \mathrm{~cm}^{-1}$ for $21 \mathrm{a}$ ), $99 \%$ monomer (via UPLC protein BEH SEC), <1\% free drug (via HiSEP HPLC), and mostly homogenous 8 drugs linked per antibody (via ESI-TOF Mass Spectrometry, and Butyl-NPR HIC chromatography). The yield for this specific inter-chain conjugation $\mathbf{m} \mathbf{A b}_{\mathbf{E}}-\mathbf{2 1 a}$ was $75 \%$.

\section{UPLC BEH SEC Method:}

The monomer percentage analysis for CAMP-ADCs was carried out on a Waters Acquity UPLC

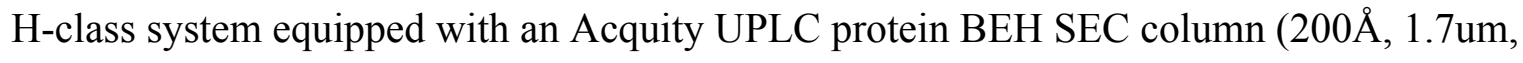
4.6mm x $150 \mathrm{~mm}$, part\# 186005225). The mobile phase was $400 \mathrm{mM}$ sodium perchloride, $50 \mathrm{mM}$ sodium phosphate, $5 \%$ IPA, $\mathrm{pH} 7.0$, flow rate $0.30 \mathrm{~mL} / \mathrm{min}$, run time $20 \mathrm{~min}$.

\section{HiSep HPLC Method:}

The free drug percentage analysis for CAMP-ADCs was performed on Agilent HPLC system equipped with a Supelco analytical HiSep column (25cm x 4.6mm, 5um, Cat\# 58919). The mobile phase consisted of 0.1 M ammonium, pH 7.0 (solvent A) and acetonitrile (solvent B). The method was run at $0.70 \mathrm{~mL} / \mathrm{min}$ with solvent $\mathrm{A}$, using a linear gradient starting from $25 \%$ solvent B to $40 \%$ solvent B from 0 - $25 \mathrm{~min}$.

\section{In vitro cytotoxicity assay:}

Cytotoxic potencies were assessed in flat-bottomed 96 well plates (Costar) as previously described. Briefly, human tumor cells (500-2,000 cells/well, depending on the cell line), in the appropriate culture medium were incubated, with conjugates in the presence or absence of an excess of the corresponding unconjugated antibodies, or with a compound, such as a metabolite, for 5 days, at $37{ }^{\circ} \mathrm{C}, 5 \% \mathrm{CO}_{2}$. Cell viability was determined by the WST-8 assay (Donjindo Molecular Technologies, Inc. ) in accordance with the manufacturer's protocol.

\section{Bystander Killing Assay:}

Cell Titer Glo, used to measure Ag+ cell viability, and One Glo, used to measure survival of Ag- cells when incubated alone or cocultured with Ag+ cells, were purchased from Promega. 
Namalwa cells stably transfected with luciferase gene to give luciferase expressing Namlawa cells (NL) were used as Ag- cells.

$\mathrm{Ag}+, \mathrm{NL}$ Ag-, or a mixture of NL Ag- cells (500 cells per well) and MDA-MB-468 Ag+ cells (1000 cells per well) in the appropriate culture media were incubated in a U-bottomed 96 well plate and $\mathrm{ADC}$ for 5 days, at $37{ }^{\circ} \mathrm{C}, 5 \% \mathrm{CO}_{2}$. On day 5 , cell viability was determined according to the manufacturer's protocols.

\section{In vivo efficacy in xenograft models:}

Female athymic Nude mice (Foxn1 ${ }^{\text {nu}}$ ) at 6 weeks of age were received from Charles River Laboratories. All in vivo procedures were performed in strict accordance with the NIH Guide for the Care and Use of Laboratory Animals. The anti-tumor activity of the ADCs was evaluated in human head and neck squamous cell carcinoma HSC-2 or non-small cell lung cancer (NSCLC) squamous H1703 tumor xenograft models. Female Nude mice were inoculated subcutaneously in the right flank with the desired cell type in 1:1 ratio of serum-free medium:Matrigel $\left(1 \times 10^{7}\right.$ cells/mouse and $5 \times 10^{6}$ cells/mouse for HSC-2 and H1703 xenografts, respectively). Tumor volumes (TV) were measured twice weekly in three dimensions using a caliper with tumor volumes expressed in $\mathrm{mm}^{3}$ calculated using the formula $\mathrm{TV}=1 / 2$ (length $\times$ width $\times$ height). Xenografts were grown to $\sim 100 \mathrm{~mm}^{3}$ and mice were randomly distributed into groups of 6 mice per group based on their TV on day 4 (HSC-2, with a $93.4+/-11.3 \mathrm{~mm}^{3}$ [mean +/- SD] TV) or day $16\left(\mathrm{H} 1703\right.$, with a $116.0+/-18.5 \mathrm{~mm}^{3}$ [mean +/- SD] TV) post cell inoculation. Stock ADCs were diluted with conjugate dilution buffer and mice were dosed by individual body weights. Mice received a single intravenous (IV) bolus injection of vehicle (phosphate-buffered saline (PBS) at $200 \mu \mathrm{L} /$ mouse) or ADC at $75 \mu \mathrm{g} / \mathrm{kg}$ or $250 \mu \mathrm{g} / \mathrm{kg}$ based on payload (approximately 3 or $10 \mathrm{mg} / \mathrm{kg}$ based on antibody concentration) at a dose volume of $5 \mathrm{~mL} / \mathrm{kg}$. Tumor growth inhibition (T/C) is the ratio of the median tumor volume (TV) of the treatment group (T) to the median TV of the control group (C) at a predetermined time (e.g. the time when the median TV for control tumors reach a maximum tumor volume $\sim 1000 \mathrm{~mm}^{3}$, which is when the mice are euthanized). According to NCI standards, a $\mathrm{T} / \mathrm{C} \leq 42 \%$ is the minimum level of anti-tumor activity and a $\mathrm{T} / \mathrm{C}<10 \%$ is considered a high anti-tumor activity level. A mouse was considered to have a partial regression (PR) when TV was reduced by $50 \%$ or greater and a complete regression (CR) when no palpable 
tumor could be detected. T/C, PR, and CR for both efficacy studies are listed in the table below. Body weights were also measured twice per week as a rough index of drug toxicity. 
Table 1. HSC-2 efficacy study results

\begin{tabular}{|c|c|c|c|c|c|}
\hline \multirow{2}{*}{ ADC (DAR) } & \multicolumn{2}{|c|}{ ADC Dose } & \multicolumn{3}{c|}{ HSC-2 } \\
\cline { 2 - 6 } & $\boldsymbol{\mu g} / \mathbf{k g}$ payload & $\mathbf{m g} / \mathbf{k g}$ Ab & T/C (Day 22) & PR & CR \\
\hline $\mathrm{ADC}_{\mathrm{Ctrl}}(7.6)$ & 259 & 10 & $70 \%$ & $0 / 6$ & $0 / 6$ \\
\hline $\mathrm{mAb}_{\mathrm{E}}-21 \mathrm{~d}(7.5)$ & 254 & 10 & $3 \%$ & $6 / 6$ & $2 / 6$ \\
\hline $\mathrm{mAb}_{\mathrm{E}}-21 \mathrm{~d}(7.5)$ & 76 & 3 & $7 \%$ & $4 / 6$ & $1 / 6$ \\
\hline $\mathrm{mAb}_{\mathrm{E}}-21 \mathrm{a}(7.5)$ & 258 & 10 & $2 \%$ & $6 / 6$ & $5 / 6$ \\
\hline $\mathrm{mAb}_{\mathrm{E}}-21 \mathrm{a}(7.5)$ & 77 & 3 & $5 \%$ & $3 / 6$ & $1 / 6$ \\
\hline
\end{tabular}

Table 2. H1703 efficacy study results

\begin{tabular}{|c|c|c|c|c|c|}
\hline \multirow{2}{*}{ ADC (DAR) } & \multicolumn{2}{|c|}{ ADC Dose } & \multicolumn{3}{|c|}{ H1703 } \\
\hline & $\mu \mathrm{g} / \mathrm{kg}$ payload & $\mathrm{mg} / \mathrm{kg} \mathrm{Ab}$ & T/C (Day 43) & PR & CR \\
\hline $\mathrm{ADC}_{\mathrm{Ctrl}}(7.5)$ & 250 & 9.9 & 58 & $0 / 6$ & $0 / 6$ \\
\hline$m A b_{E}-21 d(7.6)$ & 250 & 9.7 & 13 & $3 / 6$ & $1 / 6$ \\
\hline$m A b_{E}-21 d(7.6)$ & 75 & 2.9 & 86 & $0 / 6$ & $0 / 6$ \\
\hline$m A b_{E}-21 a(7.5)$ & 250 & 9.8 & 9 & $3 / 6$ & $0 / 6$ \\
\hline$m A b_{E}-21 a(7.5)$ & 75 & 2.9 & 69 & $0 / 6$ & $0 / 6$ \\
\hline$m A b_{E}-21 b(6.4)$ & 250 & 11.4 & 3 & $6 / 6$ & $0 / 6$ \\
\hline$m A b_{E}-21 b(6.4)$ & 75 & 3.4 & 7 & $4 / 6$ & $2 / 6$ \\
\hline
\end{tabular}

\section{Pharmacokinetic studies on $\mathrm{mAb}_{\mathrm{E}}-21 \mathrm{a}$ and $\mathrm{mAb} \mathrm{b}_{\mathrm{E}}-21 \mathrm{~d}$ ADCs in mice:}

Three groups of eleven 7-week-old female CD-1 mice were each dosed with a single intravenous bolus injection of $10 \mathrm{mg} / \mathrm{kg}$ naked antibody or ADC. Terminal blood samples were collected from 3 mice at $2 \mathrm{~min}, 3$ mice at $24 \mathrm{~h}$, and 5 mice at $72 \mathrm{~h}$ after injections for each ADC. The blood was processed to serum and the ADCs were purified using affinity capture with antihuman Fc beads. The samples were analyzed by anti-human-IgG-H+L ELISA to determine the concentration of the antibody component (irrespective of payload loading). Concentrations were determined based on $\mu \mathrm{g}$ of the $\mathrm{mAb}$ component per $\mathrm{mL}$ of serum. In addition, the samples were assayed for cytotoxicity on target positive cells (HSC-2) or non-targeting cells (Namalwa). Briefly, cells were exposed to serial dilutions of plasma samples or control ADC (same conjugate sample, but not injected ninto mice) for 5 days, and cell viability was determined by WST- 8 assay. Then the bioactive concentration of ADC in each sample, taken at a given time (Time $\mathrm{X}$ ), was calculated by multiplying the sample dilution at $\mathrm{IC}_{50}$ by the $\mathrm{IC}_{50}$ concentration (Molar) of the control ADC. Fractional retained bioactivity was calculated by dividing the 
bioactive concentration $(\mu \mathrm{g} / \mathrm{ml})$ of Time X sample, by the bioactive concentration of sample taken at $2 \mathrm{~min}$. This number was then compared against the fractional concentration of the $\mathrm{mAb}$ component in each Time X sample determined by ELISA.

\section{Mouse tolerability of $m A b_{F}-21 a$ and $m A b_{F}-21 d A D C s:$}

The tolerability of non-cross-reactive ADCs was evaluated in female CD-1 mice by performing daily body weight measurements and clinical observations for 2 weeks following injection of the ADCs. Three groups of three mice each were dosed with an IV bolus injection of $5000 \mu \mathrm{g} / \mathrm{kg}$ based on payload of $\mathbf{m} \mathbf{A b}_{\mathbf{F}}-\mathbf{2 1} \mathbf{a}\left(184 \mathrm{mg} / \mathrm{kg}\right.$ based on antibody) or $\mathbf{m} \mathbf{A b}_{\mathbf{F}}-\mathbf{2 1 d}(198 \mathrm{mg} / \mathrm{kg}$ antibody). The maximum tolerated dose (MTD) was defined as the highest dose at which no animals died or were required to be euthanized due to $>20 \%$ body weight loss or signs of distress or morbidity (hunching, lack of movement, inability to eat or drink, or signs of pain/distress). GraphPad was used for statistical analyses of the body weights in each group (two-way ANOVA with a Tukey's multiple comparisons test showed that the $\mathbf{m} \mathbf{A} \mathbf{b}_{\mathbf{F}}-\mathbf{2 1 d}$ group was significantly different from both the vehicle and $\mathbf{m} \mathbf{A b}_{\mathbf{F}}-\mathbf{2 1 a}$ groups, $\mathrm{p}<0.05$ ). 